\title{
The utilisation of a career conversation framework based on Schein's career anchors model
}

\begin{abstract}
Authors:
Magda Bezuidenhout ${ }^{1}$

Anton Grobler ${ }^{1}$

Elizabeth C. Rudolph ${ }^{1}$

Affiliations:

${ }^{1}$ Department of Human

Resource Management,

University of South Africa,
\end{abstract}

South Africa

Correspondence to:

Magda Bezuidenhout

Email:

bezuiml@unisa.ac.za

Postal address:

PO Box 392, Unisa, Pretoria

0003, South Africa

Dates:

Received: 08 Aug. 2012

Accepted: 03 June 2013

Published: 24 July 2013

How to cite this article: Bezuidenhout, M., Grobler, A., \& Rudolph, E.C. (2013). The utilisation of a career conversation framework based on Schein's career anchors model. SA Journal of Human Resource Management/SA Tydskrif vir Menslikehulpbronbestuur, 11(1), Art. \#491, 10 pages. http://dx.doi.org/10.4102/ sajhrm.v11i1.491

\section{Copyright:}

(C) 2013. The Authors. Licensee: AOSIS

OpenJournals. This work is licensed under the Creative Commons Attribution License.

Read online:

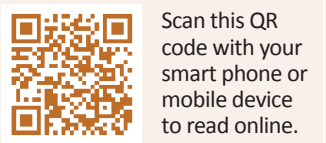

Orientation: This study constituted and reported on the outcomes of a structured career conversation framework based on Schein's eight career anchors in an open distance and e-learning (ODeL) university in South Africa.

Research purpose: The purpose of the research was to report on the utilisation of a structured career conversation framework based on Schein's career anchors model.

Motivation for the study: The rationale for the study was the paucity of studies investigating career anchors in South Africa's multicultural organisational context.

Research design, approach and method: A quantitative approach was adopted in the study. The population consisted of 4200 employees at a university in South Africa. Statistical analysis was performed using one-way analysis of variance (ANOVA) as well as a Scheffe post hoc test.

Main findings: The findings of this study suggest that career conversation has a dynamic nature (i.e. it changes) over a period of time. Consequently, career development interventions in the workplace need to approach the workforce holistically.

Practical/managerial implications: The findings and results will assist managers, practitioners and career development specialists in the practical implementation of the career anchor concept.

Contribution/value-add: The career conversation framework based on Schein's career anchors has expanded the existing theory to find the right balance between career conversations and career anchors to keep people motivated to perform optimally in an organisation.

\section{Introduction \\ Research problem}

Schein (1978:1) states that the problem for society and organisations is to match individual needs with those of the organisations throughout their entire career. Participants in a study by Coetzee and Schreuder (2009) were predominantly employed in the South African service industry, which means that their findings cannot be generalised to an open distance e-learning (ODeL) environment. To retain talented employees in an ODeL environment, it is important to understand their aspirations, in both the short and long term, and perceptions of career anchors. Therefore, there is a need to explore the following research questions:

- Do demographic variables (age, gender and race groups) play a significant role in the short and medium term regarding career anchors within a sample of respondents from a South African ODeL university work context?

- Are there significant differences between the career anchors for the short and medium term? (Does the change have dynamic or stable characteristics?)

- Are there any dominant and/or secondary career anchors for employees?

Coetzee and Schreuder (2009:118) argue that different types of careers offer different types of rewards and opportunities to satisfy work and career needs. No previous research has been conducted on the outcomes of a career conversation framework, based on Schein's eight career anchors in an ODeL university environment in South Africa. It is therefore essential to review existing approaches to dialogue between line management and employees by means of career conversations. Furthermore, limited research has previously been done on the significant differences between career anchors in different demographic groups, and in the short and medium term.

\section{Key focus of the study}

The use of career development interventions in the workplace has attracted attention in the fields of business, psychology and counselling psychology. Because human capital is one of the primary 
resources used by businesses to stay competitive in the global economy, the notion of 'career' has changed. Thus, in this article we intended to use a career conversations framework based on Schein's career anchor model and to determine the differences across demographic groups, and whether there is a dynamic change over a period of time in employees' career anchors.

\section{Background to the study}

To date, limited research has been done on career anchors in the South African multicultural organisational context. A vital indicator of the emergence of a quality culture is capacity-building efforts made by ODeL universities through continuous staff development opportunities (Jung, 2005:90). Although organisations no longer expect individuals to develop a hierarchical career in a single organisation, organisations are intensely competitive, and the ones that retain the greatest number of their employees tend to emphasise continuous learning for employees (Byrne 1999, as cited in Tan \& Quek, 2001:527). Given the strong emphasis on human capital, this study attempted to understand the fit of individuals' internal career needs (aspirations) in their jobs, based on Schein's career anchors. As a result, the ODeL organisation realised the importance of using career conversations as an intervention method to identify, formulate and escalate career development plans within employees' career portfolios. Consequently, Schein's career anchors were used to support the structure of using career conversations to determine the career aspirations of employees within an ODeL environment.

\section{Trends in the research literature}

Career conversations (between managers and employees) are considered to be a method of career development (Butterfield, Lalande \& Borgen, 2009) that may lead to a greater understanding of employees' specific expectations. Accordingly, in an effort to ensure lasting competitiveness, career development could result in attracting and retaining human capital. In the process of looking after human capital, the function of career anchors is to organise individuals' experiences, identifying the long-term contributions of individuals and establishing criteria for success against which individuals can measure themselves (Coetzee, Schreuder \& Tladinyane, 2007). Furthermore, Coetzee et al. (2007) assert that career anchors are a key determinant of an individual's choice of a career or workplace. In this respect, Schein also emphasises that a stable career identity is structured by combining an individual's interests with their abilities and values (Schein, 1993, 1996; Feldman \& Bolino, 1996). It is here that the importance of career anchors is felt, and the right balance between career conversations and career anchors may go a long way towards keeping people motivated to perform optimally in an organisation.

\section{Research objectives}

The aim of the present study was to report on the outcomes of a career conversation framework based on Schein's eight career anchors in an ODeL university environment in South
Africa. Furthermore, to retain talented employees in an ODeL environment, it is important to understand their aspirations, in both the short and long term, and perceptions of career anchors. The objectives of the study were to investigate:

- The significant role of demographic variables (age, gender and race groups) in the short and medium term regarding career anchors within a sample of respondents from a South African ODeL university work context;

- The significant differences between career anchors for the short and medium term, and whether the change has dynamic or stable characteristics;

- Whether dominant and/or secondary career anchors exist for employees within the organisation.

\section{Potential value-add of the study}

Career development in today's economy requires a dynamic reciprocal process in which the employee is willing to engage in career development and the employer is willing to allocate the resources to encourage it. However, despite the advantages career development provides, few career development services, such as career conversations, are available for employees in higher educational institutions. This study could add new knowledge and insight to improve career conversation practices that will have a positive influence on the bottom line of a business for managers and employees alike.

\section{Literature review}

During the 60s, 70s, 80s and 90s, Schein's work introduced the operationalisation of the multi-dimensional use of career anchors and their relationship to career success (Coetzee \& Schreuder, 2009; Singh, Bhattacharjee \& Kodwani, 2009). Organisations are dependent on the performance of their employees, and employees are dependent on organisations to provide jobs and career opportunities (Schein, 1978:1). Feldman and Bolino (1996) suggested alternative methodologies for measuring and analysing career anchor data; they also explored the implications of career anchor research for managing careers in organisations. Feldman and Bolino were of the opinion that career anchor theory has focused mainly on adults in their 30 s and 40s, and its implications for university placement centres have been largely ignored. Coetzee and Schreuder (2009) found valuable new knowledge that can be used to inform organisational career development support practices as well as career counselling and guidance services within a South African context.

\section{Career anchors and their categories}

After 1978, Edgar Schein's work led to the development of the following eight career anchors that guide the career decisions of employees (Schein, 1990:4-11): (1) security, stability or organisational identity, (2) autonomy and independence, (3) creativity and entrepreneurship, (4) technical or functional competence, (5) managerial competence, (6) sense of service or dedication to a cause, (7) pure challenge, and (8) lifestyle integration. Schein (1985:1) argues that a career anchor 
is a person's self-image, indicating what they excel in and their wants and values. Feldman and Bolino (1996:89) reconceptualised the nature of Schein's eight career anchors into the following three career enabler groupings: (1) talentbased anchors, (2) value-based anchors and (3) need-based anchors.

Scholars differentiate between (and do not necessarily concur about the relative importance of) two dimensions of career anchors, namely internal and external careers (Schein, 1980, 1987; Tan \& Queck, 2001; Hassan et al., 2012). Added to this, Schein (1993) points out that, for future decisionmaking purposes, individuals need to clearly understand their orientation towards work, their motives, their values and their self-perceived talents. Schein (2006) further argues that successful organisational performance and productive, satisfying careers are ultimately a process of matching the ever-changing needs of an organisation and those of the individual. Consequently, Schreuder and Coetzee (2006:221) gave an integrated overview of the concept of career anchors and career enablers by allocating characteristics to them (see Table 1). Wils, Wils and Tremblay (2010:236) concur with Schein that an individual progresses through their career as a result of the interaction between the individual and the workplace (Wils et al., 2010:236).

TABLE 1: Characteristics of the eight career anchors.

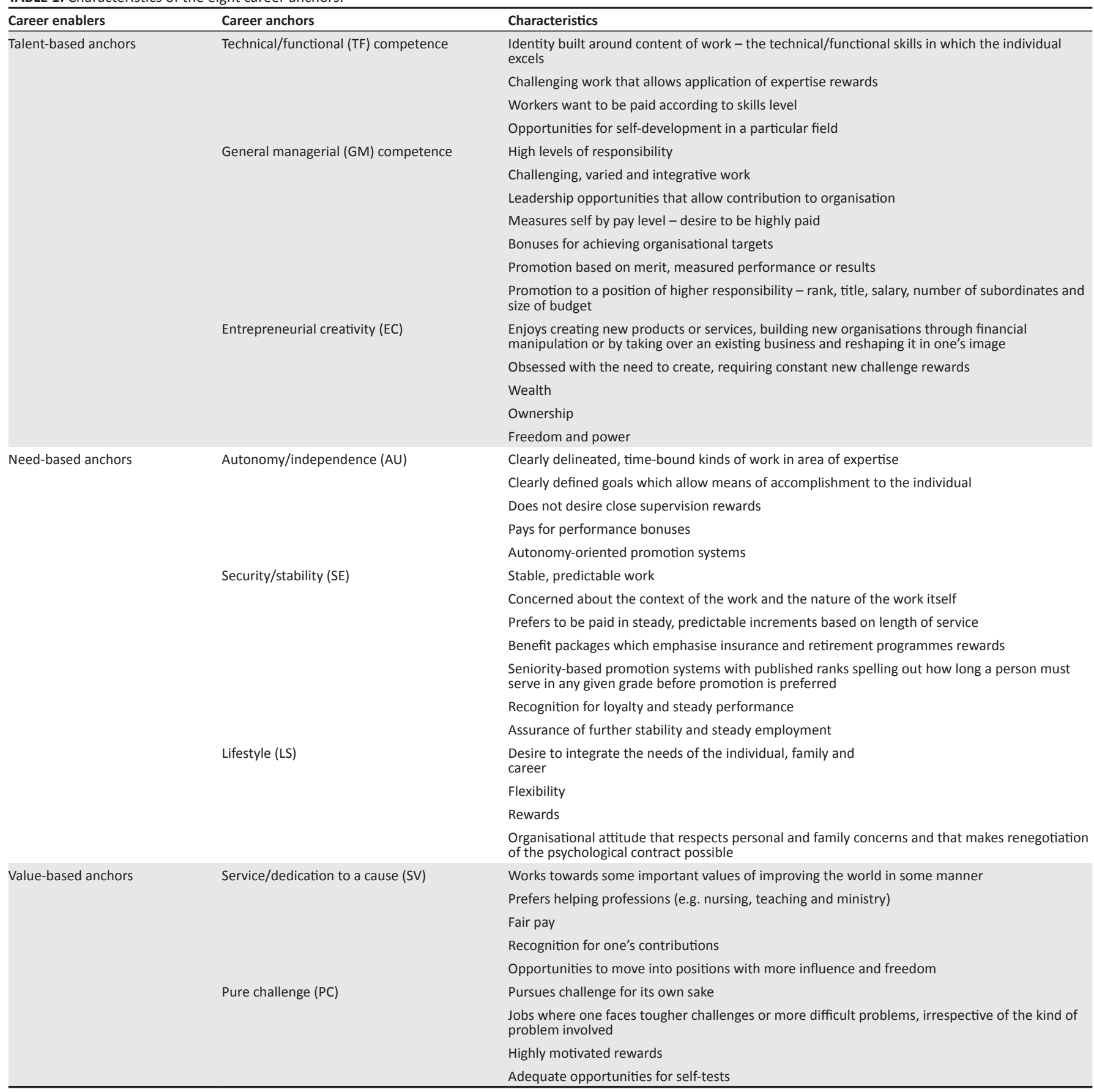

Source: Adapted from Schreuder, A.M.G. \& Coetzee, M., 2006, Careers: An organisational perspective, 3rd edn., Juta, Cape Town, p. 221. 


\section{The rather static nature of career anchors}

Owing to the 'ever-changing' nature of the needs of organisations and individuals, Schein (2006) contends that early in a person's career, they value many things and do not yet know what they would hold on to if forced to make a choice. Schein maintains that the further into a career a person progresses, the greater the likelihood of there being only one anchor. However, Weber and Ladkin (2009) found (from a small sample size) that a multitude of career anchors guide industry professionals' careers, regardless of whether there is a single dominant or a multiplicity of anchors.

\section{The impact of demographic variables (age, gender and race) on career anchors}

Coetzee et al. (2007) (with a sample of 157 part-time students at a university) reported significant differences between the career anchors of males and females, as well as a number of significant differences between two variables (only $0.03 \%$ of the commitment variance, while the commitment variables explained $0.40 \%$ of the career anchors variance). Coetzee and Schreuder (2009:117) explored the relationship between the psychological career resources and career anchors of a sample of 2997 working adults at predominantly managerial and supervisory levels in the service industry. The Psychological Career Resources Inventory and the Career Orientations Inventory were applied and their findings indicated dimensions of psychological career resources as significant predictors of participants' career anchors. Singh et al. (2009) conducted a study in a large engineering company with 1433 executives, across all age groups and different cultural backgrounds. Service orientation, technical competence and lifestyle surfaced as the dominant anchors for the majority of respondents in their study. Furthermore, Hassan et al. (2012:61) argue that individuals with a higher level of competence tend to avoid decisions that lead to managerial jobs and attempt to remain in their interested technical groups. No specific literature was found regarding the impact of race on career anchors.

\section{Differences between primary and secondary career anchors}

The main assumption underpinning Schein's (1985) career anchors is that there can only be one career anchor. Scholars further differentiate between (and do not necessarily concur about the relative importance of) two dimensions of career anchors, namely internal and external careers. Ituma and Simpson (2006) suggested the existence of multiple career anchors. Career anchors evolve only as one gains occupational and life experience. Schein (2006:15) is convinced that once the self-concept has been formed, it functions as a stabilising force - an anchor - and can be regarded as the values and motives a person will not relinquish if forced to make a choice. However, it is essential to be aware of career anchors so that wise career decisions can be made. This suggests that individuals will seek job opportunities that strengthen an anchor rather than undermine it (Ituma \& Simpson, 2006:980). Consequently, Coetzee et al. (2007:69) argue that Schein's own empirical evidence suggested that individuals can strongly hold more than one career anchor. Schein (2006) argues that change is possible, and that there are instances of this, but that the odds are against change for several reasons. Schein further states that the development of selfinsight in a person provides security and direction and leads to the unknown becoming known. Schein (2006) further maintains that the more people know about themselves as they age, the more stable they become and the more they wish to remain stable. Consequently, this study attempted to stimulate career conversations between employees and line management based on a framework according to the eight career anchors of Schein. Further, the study attempted to capture and give meaning to the important human resource function to develop an intervention framework as part of career management within an ODeL environment.

\section{Career conversations and the use of career anchors}

Ramsey (1998) posits that managers can change perceptions, actions and relations by 'managing within conversation'. Hence, dialogue between line management and employees may instil meaning and mutuality to enhance decision making, group functions and overall productivity (Walsh \& Fisher, 2005). De Vos and Hauw (2010) argue that it is not sufficient for organisations merely to provide a series of training, on-the-job learning and career development practices. The Chartered Institute of Personnel Development's (CIPD's) Managing Employee Careers Survey shows that the majority of organisations expect employees to take responsibility for their own careers, but recognise that employees need support and training for this (CIPD 2005). Kidd, Hirsh and Jackson (2004) dispute the contention that organisations need to reposition the responsibility for presenting career support to employees in the context of a face-to-face discussion (conversation).

To compete in today's rapidly evolving global economy, people need to find out what their career anchors are in order to make smart future plans (Schein, 2006). Organisational commitment is one of the factors that can influence career anchors of employees. Therefore, Hassan et al. (2012) examined the relationship between career anchors and organisational commitment among faculty members at the University of Urmia. Their empirical study was based on a sample of 70 faculty members. The findings indicate that there was a positive relationship between career anchor components and organisational commitment components among members of the study group. Technical functional competence, general managerial competence, autonomy/ independence, pure challenge and lifestyle were found to be significant predicators of organisational commitment. Feldman and Bolino (1996:90) argue that, if an individual has to make decisions about what jobs to pursue and how to balance their personal and work life, career anchor functions remain a constraining force. Furthermore, Coetzee et al. (2007:81) suggest that career anchors are not significant predictors of organisational commitment. Tan and Queck (2001:528) posit that career anchors function as stabilising forces in guiding future career directions and decisions and can be regarded as the values and motives that an individual will not relinquish if forced to make a choice. 
Ituma and Simpson (2006:980) state that it is unlikely that Schein's US-based framework, which gives a reflection of a unique set of social structures and organisations, will fully capture the career orientations of individuals in different national contexts, because of the likely impact of societal organisations and national culture. Consequently, a career conversation framework was developed by the human resource department of the above mentioned South African ODeL, using Schein's eight career anchors, to explore the career orientations of the employees (considering demographic factors such as age, gender and race).

The word 'career' has different connotations for different people. Schein (2006:5) argues that organisations realise the importance of satisfying careers and that these are ultimately the product of a good process of matching the ever-changing needs of organisations with the ever-changing needs of an individual's career. It is seen in the context of (1) how society perceives an individual's journey through their work life, (2) advancement in their professional life and (3) how the individual evolves with their work experience over time (Singh et al., 2009:51). Therefore, organisations have to face the challenge of retaining their best and most talented staff by means of career conversations. Additionally, this article facilitates career planning and conversations and enables both the individual and the organisation to fulfil their needs.

The next section of the article will elaborate on the research design, approach and method that was adopted in this study. This is followed by the results and a discussion of the findings. The article concludes with a brief synopsis of the main conclusions, implications for practice and recommendations for future research.

\section{Research design \\ Research approach}

For this explorative and descriptive study, a quantitative survey research approach was used to achieve the research objectives (Babbie \& Mouton, 2007).

\section{Research method}

\section{Research participants}

The participants were drawn from a population of 4200 employees: a sample of 1383 employees (from different departments: professional, support and academic) in an open distance e-learning university in South Africa were interviewed. Daniel 2006 (cited in Latchem et al., 2006:221) define ODeL universities as distance education organisations with enrolments of over 100000 that have increased participation while markedly reducing costs. Table 2 indicates the demographic characteristics of the respondents.

The results in Table 2 show that a total of 1392 valid datasets were received and analysed. Of the respondents, $53.6 \%$ were African people, $38.9 \%$ White people, $4.0 \%$ of mixed race and $3.5 \%$ Indian people. All race groups were represented and approximately one-third of the population responded (34.4\%). A more or less even distribution in terms of gender was reported, with $54.5 \%$ of the respondents being women and $45.5 \%$ men. Furthermore, the academic management and primary support categories were best represented, with $90.9 \%$ and $46.5 \%$ respectively. The academic core and the institutional support categories had smaller representation, with $19.7 \%$ and $20.2 \%$ respectively. The average representation across the categories was $38.8 \%$. The majority

TABLE 2: Characteristics of the study population.

\begin{tabular}{|c|c|c|c|c|}
\hline Item & Category & $n$ & $\%$ of respondents & $\%$ of population \\
\hline \multirow[t]{4}{*}{ Race } & African people & 746 & 53.6 & 33.3 \\
\hline & Mixed race & 55 & 4.0 & 37.6 \\
\hline & Indian people & 49 & 3.5 & 34.0 \\
\hline & White people & 542 & 38.9 & 32.5 \\
\hline \multirow[t]{2}{*}{ Gender } & Female & 759 & 54.5 & 32.3 \\
\hline & Male & 633 & 45.5 & 32.6 \\
\hline \multirow[t]{5}{*}{ Age (years) } & $18-20$ & 50 & 3.6 & - \\
\hline & $21-25$ & 313 & 22.5 & - \\
\hline & $26-35$ & 643 & 46.2 & - \\
\hline & $36-55$ & 328 & 23.6 & - \\
\hline & $56-65$ & 58 & 4.2 & - \\
\hline \multirow{2}{*}{$\begin{array}{l}\text { Distribution according to broad } \\
\text { personnel category }\end{array}$} & Professional \& support & 1109 & 79. & 38.3 \\
\hline & Academic & 283 & 20.3 & 20.1 \\
\hline \multirow{6}{*}{$\begin{array}{l}\text { Distribution according to the } \\
\text { differentiated personnel model }\end{array}$} & Academic management & 10 & 0.7 & 90.0 \\
\hline & Academic support & 77 & 5.5 & 22.5 \\
\hline & Institutional management & 10 & 0.7 & 33.3 \\
\hline & Institutional support & 112 & 8.1 & 20.2 \\
\hline & Primary management & 14 & 1.0 & 38.3 \\
\hline & Primary support & 895 & 64.3 & 46.5 \\
\hline \multirow[t]{2}{*}{ Studying further } & No & 718 & 51.6 & - \\
\hline & Yes & 608 & 43.7 & - \\
\hline
\end{tabular}


of respondents were in the 26 to 35 age group (46.2\%) with a normal distribution across the categories. Table 2 also shows that the professional and support categories of the university had a significantly higher response rate with $38.3 \%$ of the population, while $20.1 \%$ of the academic population participated in the career conversations. Of the respondents, $43.7 \%$ were studying further, while $51.6 \%$ indicated that they were not. A total of 66 respondents did not complete this field. It is evident from the results that all the demographic groups were well represented in this study, including the race, gender, age, broad personnel category, further studies and detailed human resource category.

\section{Measuring instrument}

An element of qualitative data was included through structured interviews (conversations) with employees (Silverman, 2010). The respondents were allowed to make comments during the structured interview. However, the focus in this article is not to report in depth on the comments collected. The interview measured eight career preferences (see Table 2 for the eight career anchors). The career planning conversation framework was used by each line manager and comprised the three sections. Section 1 focused on the employee's current goals (to determine whether the individual would like to make a vertical or horizontal career move), while section 2 included a 'career preference' (based on Schein's career anchors) table. The line managers were requested to determine the three top career preferences of each employee (to be used during the career conversations). Section 3 focused on the role of the line manager and included a career preference table, with a 'possible actions' column and an 'agreed actions' column. The career conversation framework made provision for choosing between the three career enablers, but the focus of the analysis was on Schein's eight career anchors.

\section{Research procedure}

The results were captured and consolidated by means of an electronic system, administered by the Directorate of Organisation Development via personalised email messages to all line managers. The line managers were requested to use a career conversation framework (structured interviews with clear guidelines) and to record and capture the responses on the electronic system. Biographical data were obtained from the university's human resource information system.

The demographical factors of the instrument included variables such age, race, gender, language and highest qualification, as well as an indication of whether the respondent was busy with further studies.

\section{Statistical analysis}

The statistical analysis was conducted by means of Statistica version 10, a statistical program. Descriptive statistical data analysis (means, skewness and kurtosis) was used. A statistical analysis was performed using one-way analysis of variance (ANOVA). When the overall ANOVA showed significant differences between groups, a Scheffe post hoc test was used to determine the pairs of groups that were different. The accepted level of significance was $p<0.05$. The practical significance of differences in means between the groups was determined (Ravid, 2010:150). Cronbach's alpha coefficients and interim correlations were used to determine the validity and reliability of the constructs measured in the career conversations framework. The Cronbach alpha determines the internal consistency of a test or scale and is articulated as a number between 0 and 1 (Tabachnick \& Fidell, 2007). Adequate measuring values of the Cronbach alpha range from 0.70 to 0.95 (Tabachnick \& Fidell, 2007). The career conversations survey was consistently used and hence was seen as reliable indicators (see Table 3).

\section{Results}

The results of the study relate to the research questions, which were based on the career conversations that took place in the university.

\section{Differences between the groups in terms of their career anchors in the short term ( 1 to 3 years) and medium term ( 4 to 10 years)}

Significant statistical differences were determined between the different groups and are indicated in terms of the short and medium term (see Tables 4 to 9). Statistically significant differences are reported in Table 4 in terms of race and career anchors in the short term. The African group measured significantly higher than the White group on the technical/ functional and general managerial career anchors. The White group measured significantly lower than all other race groups on the general managerial career anchor. The security or stability career anchor was significantly more important to the White group than the African group. Lifestyle was also significantly more important to the White group compared with the African and Indian groups.

TABLE 3: Descriptive statistics and Cronbach alpha coefficient of the career anchors.

\begin{tabular}{|c|c|c|c|c|c|c|}
\hline Items & Factor & Mean & SD & Skewness & Kurtosis & Cronbach alpha $(\alpha)$ \\
\hline 6 & Technical/functional & 4.26 & 2.04 & -1.10 & 0.00 & 0.80 \\
\hline 5 & General managerial & 3.51 & 2.02 & -0.90 & -0.90 & 0.92 \\
\hline 6 & Autonomy/independence & 3.82 & 2.39 & -0.70 & -1.20 & 0.92 \\
\hline 6 & Security/stability & 2.23 & 1.48 & -0.50 & -1.20 & 0.76 \\
\hline 4 & Entrepreneurial creativity & 1.53 & 1.37 & 0.00 & -1.80 & 0.91 \\
\hline 3 & Sense of service/dedication to a cause & 1.95 & 1.34 & -0.60 & -1.50 & 0.93 \\
\hline 3 & Autonomy/independence & 1.79 & 1.36 & -0.40 & -1.70 & 0.92 \\
\hline 4 & Lifestyle & 2.47 & 1.57 & -0.60 & -1.20 & 0.85 \\
\hline
\end{tabular}


Table 5 indicates that the White group measured significantly lower than the African and mixed race groups on the general managerial anchor and lower than the African group on the entrepreneurial creativity anchor in the medium term. The White group measured significantly higher than the African group on the lifestyle anchor.

Table 6 indicates that the technical/functional, autonomy/ independence and lifestyle career anchors were significantly more important to the female group than the male group in the short term, while the general managerial anchor was more important to the male group than the female group in the short and medium term. The male respondents also measured significantly higher on the self-transcendence and self-enhancement career enablers.
Table 7 indicates that the male group measured significantly higher on the general managerial anchor in the medium term compared with the female group.

The importance of the technical/functional career anchor in the short term decreased significantly with age (see Table 8), with the 18 to 20 age group rating it the highest and the 56 to 65 age group the lowest. The general managerial career anchor measured significantly higher for the 21 to 25 age group than the other age groups and the 26 to 35 age group was higher than the 36 to 55 age group which in turn was higher than the 56 to 65 age group. No significant differences were reported on the other career anchors.

Table 9 shows that the 56 to 65 age group measured significantly lower than the other age groups on the

TABLE 4: Career anchors and race in the short term (1 to 3 years).

\begin{tabular}{llllllll}
\hline Race & TF & GM & AU & SE & EC & SV & PC \\
\hline African people & $1.69^{1}$ & $1.25^{1}$ & 0.50 & $0.41^{1}$ & 0.29 & 0.57 & 0.37 \\
Mixed race & 1.47 & $1.36^{2}$ & 0.49 & 0.65 & 0.22 & 0.72 & 0.29 \\
Indian people & 1.80 & $1.29^{3}$ & 0.51 & 0.57 & 0.14 & 0.43 & 0.55 \\
White people & $1.47^{1}$ & $0.72^{1,2,3}$ & 0.62 & $0.68^{1}$ & 0.32 & 0.52 & 0.43 \\
\hline
\end{tabular}

TF, Technical/functional competence; GM, General managerial competence; EC, Entrepreneurial creativity; AU, Autonomy/independence; SE, Security/stability; LS, Lifestyle; SV, Service/ dedication to a cause; PC, Pure challenge.

$1,2,3$, Statistical significant difference at $p<0.05$ in the column.

TABLE 5: Career anchors and race in the medium term (4 to 10 years).

\begin{tabular}{llllllll}
\hline Race & TF & GM & AU & SE & EC & SV & PC \\
\hline African people & 0.89 & $1.38^{1}$ & 0.52 & 0.62 & $0.49^{1}$ & 0.47 & 0.43 \\
Mixed race & 0.76 & $1.47^{2}$ & 0.62 & 0.68 & 0.33 & 0.42 & 0.22 \\
Indian people & 0.76 & 1.16 & 0.55 & 0.84 & 0.41 & 0.61 & 0.33 \\
White people & 0.76 & $0.69^{1,2}$ & 0.56 & 0.95 & $0.33^{1}$ & 0.40 & 0.27
\end{tabular}

TF, Technical/functional competence; GM, General managerial competence; EC, Entrepreneurial creativity; AU, Autonomy/independence; SE, Security/stability; LS, Lifestyle; SV Service/dedication to a cause; PC, Pure challenge.

$1,2,3$, Statistical significant difference at $p<0.05$ in the column.

TABLE 6: Career anchors and gender in the short term (1 to 3 years).

\begin{tabular}{llllllll}
\hline Gender & TF & GM & AU & SE & EC & SV & PC \\
\hline Female & $1.62^{*}$ & $0.89^{*}$ & $0.60^{*}$ & 0.53 & 0.28 & 0.54 & 0.41 \\
Male & $1.57^{*}$ & $1.24^{*}$ & $0.49^{*}$ & 0.53 & 0.31 & 0.57 & 0.38 \\
\hline
\end{tabular}

TF, Technical/functional competence; GM, General managerial competence; EC, Entrepreneurial creativity; AU, Autonomy/independence; SE, Security/stability; LS, Lifestyle; SV, Service/dedication to a cause; PC, Pure challenge.

$*, p<0.05$ in the column.

TABLE 7: Career anchors and gender in the medium term (4 to 10 years).

\begin{tabular}{llllllll}
\hline Gender & TF & GM & AU & SE & EC & SV & PC \\
Female & 0.81 & $1.03^{*}$ & 0.56 & 0.67 & 0.38 & 0.44 & 0.38 \\
Male & 0.84 & $1.19^{*}$ & 0.51 & 0.65 & 0.46 & 0.45 & 0.39 \\
\hline
\end{tabular}

TF, Technical/functional competence; GM, General managerial competence; EC, Entrepreneurial creativity; AU, Autonomy/independence; SE, Security/stability; LS, Lifestyle; SV, Service/dedication to a cause; PC, Pure challenge.

$*, p<0.05$ in the column.

TABLE 8: Career anchors and age in the short term (1 to 3 years).

\begin{tabular}{llllllll}
\hline Age group & TF & GM & AU & SE & EC & SV & PC \\
\hline $18-20$ years & $2.08^{1}$ & 0.86 & 0.32 & 0.56 & 0.30 & 0.58 & 0.50 \\
$21-25$ years & $1.83^{2,3}$ & $1.15^{1,2}$ & 0.48 & 0.46 & 0.31 & 0.52 & 0.42 \\
$26-35$ years & 1.55 & $1.20^{3,4}$ & 0.57 & 0.49 & 0.27 & 0.58 & 0.40 \\
$36-55$ years & $1.49^{2}$ & $0.81^{1,3}$ & 0.60 & 0.66 & 0.34 & 0.54 & 0.40 \\
$56-65$ years & $1.09^{1,3}$ & $0.33^{2,4}$ & 0.53 & 0.57 & 0.21 & 0.48 & 0.17 \\
\hline
\end{tabular}

TF, Technical/functional competence; GM, General managerial competence; EC, Entrepreneurial creativity; AU, Autonomy/independence; SE, Security/stability; LS, Lifestyle; SV: Service/ dedication to a cause; PC, Pure challenge.

dedication to a cause; PC, Pure challenge.
1,3 , Staistical significant difference at $p<0.05$ in the column. 
TABLE 9: Career anchors and age in the medium term (4 to 10 years).

\begin{tabular}{llllllll}
\hline Age group & TF & GM & AU & SE & EC & SV & PC \\
\hline $18-20$ yrs & $1.18^{1}$ & $1.48^{1,2}$ & 0.46 & 0.38 & 0.66 & 0.40 & 0.54 \\
$21-25$ yrs & $1.91^{2}$ & $1.55^{3,4,5}$ & 0.50 & 0.65 & $0.57^{1,2}$ & 0.42 & 0.40 \\
$26-35$ yrs & $1.88^{3}$ & $1.23^{3,6,7}$ & 0.62 & 0.70 & 0.40 & $0.53^{1}$ & $0.48^{3}$ \\
$36-55$ yrs & 1.69 & $0.56^{1,4,6}$ & 0.50 & 0.70 & $0.32^{1}$ & 0.36 & 0.35 \\
$56-65$ yrs & $0.26^{1,2,3}$ & $0.00^{2,5,7}$ & 0.2 & 0.43 & $0.17^{2}$ & $0.16^{1}$ & $0.07^{2,3}$ \\
\hline
\end{tabular}

TF, Technical/functional competence; GM, General managerial competence; EC, Entrepreneurial creativity; AU, Autonomy/independence; SE, Security/stability; LS, Lifestyle; SV: Service/dedication to a cause; PC, Pure challenge.

$1,2,3,4,5,5,6,7, p<0.05$ in the column

TABLE 10: Primary and secondary career anchors in the short term (1 to 3 years).

\begin{tabular}{lclll}
\hline Career anchor & Primary & $\%$ & Secondary & $\%$ \\
\hline Technical/functional & 597 & 45.6 & 182 & 16.0 \\
General managerial & 304 & 23.2 & 232 & 20.3 \\
Autonomy/independence & 91 & 7.0 & 178 & 15.6 \\
Security/stability & 101 & 7.7 & 143 & 12.5 \\
Entrepreneurial creativity & 40 & 3.1 & 85 & 7.5 \\
$\begin{array}{l}\text { Sense of service/ } \\
\text { dedication to a cause }\end{array}$ & 90 & 6.9 & 162 & 14.2 \\
$\begin{array}{l}\text { Pure challenge } \\
\text { Lifestyle }\end{array}$ & 53 & 4.0 & 107 & 9.4 \\
\hline
\end{tabular}

TABLE 11: Primary and secondary career anchors in the medium term (4 to 10 years).

\begin{tabular}{lllll}
\hline Career anchor & Primary & $\%$ & Secondary & $\%$ \\
\hline Technical/functional & 269 & 22.6 & 141 & 13.4 \\
General managerial & 405 & 34.0 & 131 & 12.5 \\
Autonomy/independence & 104 & 8.7 & 171 & 16.3 \\
Security/stability & 147 & 12.4 & 160 & 15.2 \\
Entrepreneurial creativity & 84 & 7.1 & 127 & 12.1 \\
$\begin{array}{l}\text { Sense of service/ } \\
\text { dedication to a cause }\end{array}$ & 69 & 5.8 & 134 & 12.7 \\
$\begin{array}{l}\text { Pure challenge } \\
\text { Lifestyle }\end{array}$ & 63 & 5.3 & 106 & 10.1 \\
\hline
\end{tabular}

technical/functional, general managerial, entrepreneurial creativity, sense of service/dedication to a cause and pure challenge career anchors in the medium term. There was a general trend of a significant decrease in scores as age increased on the general managerial, entrepreneurial creativity and pure challenge career anchors. The 26 to 35 age group measured significantly higher on the sense of service/ dedication to a cause career anchor compared with the 56 to 65 age group. Lifestyle in the next ten years was significantly more important to the 21 to 25 age group than the 36 to 55 age group.

The primary and secondary career anchors of the respondents are discussed in the section below.

\section{Differences between the career anchors in the short and medium term}

Table 10 indicates that the technical/functional career anchor seems to be the most common primary career anchor in the short term at the university with a $45.6 \%$ prevalence, followed by the general managerial anchor at $23.2 \%$. The rankings of the lifestyle, entrepreneurial creativity and pure challenge anchors were low in comparison with those two. Since the technical/functional anchor was chosen by nearly $46 \%$ of the respondents as their primary career anchor, the distribution was more even in terms of the secondary career anchors (see Table 10), with the general managerial, technical/functional and autonomy/independence anchors at 20.3\%, 16.0\% and $15.6 \%$ respectively.

The difference between the overall distribution for the short and medium terms was significant (as indicated in Table 11) in that the predominant primary career anchor was general managerial in the medium term, followed by the technical/ functional anchor. Security/stability, entrepreneurial creativity, pure challenge and lifestyle measured slightly higher in comparison with the primary career anchors measured over the short term.

\section{Discussion}

As stated earlier, the purpose of the present article was to report on the outcomes of a career conversation framework based on Schein's eight career anchors in an ODeL university in South Africa. An attempt was also made to report on how the study could help organisations to retain talented employees in an ODeL environment by understanding their aspirations in the short and long term and their perceptions of career anchors.

\section{Differences between the groups in terms of their career anchors in the short term ( 1 to 3 years) and medium term (4 to 10 years)}

\section{Difference between the groups in terms of their career anchors in the short term and medium term: Race group}

The study shows a significant difference between the African and White groups in terms of their career anchors in the short and medium term. In the short term, the results of the African group show that they would rather focus on technical/functional and general managerial career anchors. It is therefore assumed that although the African group appeared to have a great need to develop as managers, they indicated that they would prefer to have the necessary technical/functional skills in the short term. However, in the short term, the White group indicated that they would rather focus on the security/stability and lifestyle career anchors.

Interestingly, in the medium term, the African group indicated that they would like to focus on their entrepreneurial creativity anchor, but still had a need to focus on the general managerial anchor. In the medium term, the White group's focus was on the lifestyle anchor. One could therefore infer that both the 
African and the White group kept their focus on one career anchor (either general managerial or lifestyle) between the short and the medium term. Singh et al.'s (2009) study on different cultural backgrounds found that the dominant career anchors were service orientation, technical/functional and lifestyle. These results make a significant contribution to the literature because they indicate a significant difference between the predominant career aspirations of the African and White groups in the short and medium term.

\section{Difference between the groups in terms of their career anchors in the short and medium term: Gender group}

The female group preferred to focus in the short term on the technical/functional, autonomy/independence and lifestyle career anchors, whereas the male group preferred to focus only on the general managerial anchor in the short term. In the medium term, only one career anchor, general managerial, stood out above the other career anchors. However, the male group did measure significantly higher on the general managerial anchor compared with the female group. It would thus appear as if the career anchor for the male group remained the same.

The results for the short-term period concur with those of Coetzee et al.'s (2007) study, namely that there is a significant difference between the gender groups. However, it should be noted that the only career anchor that indicated a significant difference between the gender groups was the general managerial anchor. It can thus be assumed that some respondents in the female group changed their focus from technical/functional, autonomy/independence and lifestyle career anchors to a general managerial anchor in the medium term. This seems to indicate that there was a small dynamic change in the nature of the career aspiration of the female group between the short and medium term. The dynamic nature of change in the career aspirations of the female group appears to concur with the results of the study of Feldman and Balino (1996) regarding the constraining force of career anchors on work or life balance.

\section{Difference between the groups in terms of their career anchors in the short and medium term: Age group}

The results of the study in the short term indicate that the importance of the technical/functional career anchor appears to decrease as employee's age. In addition, the 21 to 25 age group demonstrated a great need for the general managerial career anchor. However, in the medium term, the focus of the career anchors changed.

The technical/functional, general managerial, entrepreneurial, service/dedication and pure challenge career anchors measured significantly lower for the other age groups in the medium term. The 21 to 25 age group seems to prefer focusing on the career anchor lifestyle, whereas the 26 to 35 age group appears to opt for service/dedication. It is interesting to note that these results add extra value to the literature on Schein's career anchors because age appears to impact on employees' decisions about the career anchors on which they would like to focus. This seems to concur with Ituma and Simpson's (2006) research that multiple career anchors evolve as a person gains occupational and life experience.

\section{Are there any dominant and/or secondary career anchors for employees?}

The results indicate that the respondents' dominant career anchors fluctuated between either technical/functional or general managerial. However, in the medium term a significant difference was evident between the primary and secondary career anchors. The primary anchors were predominantly the general managerial and the technical/ functional career anchor (i.e. more or less the same as in the short term). However, the secondary career anchors changed for the respondents towards a focus on the autonomy/ independence, service/dedication, pure challenge and lifestyle career anchors in the medium term. Hence, although the dominant career anchor appears to be general managerial, in this study the results clearly show that the respondents in this study had multiple career anchors. These results thus concur with the results of the study by Feldman and Bolino (1996), namely that multiple career anchors do exist.

\section{Limitations of the study}

The present study was limited to a population in a South African ODeL environment and cannot be generalised to other industries. The structured nature of the interviews limited in-depth information and no reporting was done on the qualitative data of the study.

\section{Suggestions for future research}

The findings contribute new knowledge to the field of career psychology and human resource management. In order to generalise the results, future research on this study would be required in different industries. If an organisation wishes to promote career development for specific diverse groups, different career advancement strategies should be considered. The findings of this study highlight the need for debates on the process of matching the ever-changing needs of an organisation and of the individual. Hence the use of Schein's career anchors in a career conversation framework creates a dialogue between management and employees to ensure a better fit between the needs of the organisation and those of the individual.

\section{Conclusion}

The main requirement for organisations is to remain competitive, which necessitates effective communication of expectations between employees and employers (discussions about needs, values and career orientations). Career paths can be structured and mapped using Schein's career anchors in a constructive succession plan at the highest levels of the organisation. Although the main responsibility for an individual's career success is in their own hands, the organisation as the employer needs to create an enabling environment to achieve success (further research will follow based on Feldman and Bolino's [1996:89] theory). This has implications for organisational staff policies. 
In terms of the ever-changing nature of the needs of organisations and individuals, Schein (2006:15) contends that a person values many things early in their career and does not yet knows what they would hold on to if forced to make a choice. Schein (2006) maintains that as a person progresses further in their career, they are more likely to have only one anchor. However, the results of this study contradict Schein's argument regarding the likelihood of having only one anchor.

Demographic factors influence whether the change in career anchors in an individual's career is static or dynamic between the short and medium term. In conclusion, an organisation's intervention processes need to visualise a clear dynamic career conversation between line management and the employee. In terms of the research questions, the statistical analysis suggests that the career anchor results in the short term (1 to 3 years) and medium term ( 4 to 10 years) indicate a dynamic change in the career anchors over time.

Owing to the fact that South Africa's workforce is so diverse, organisations need to adopt a holistic perspective towards their career development interventions. Further research is therefore needed to develop this holistic view. The dynamic nature (change) over time between the different groups was clear. The researchers concluded that Schein's career anchors could be a useful tool in the use of career conversations. Businesses and psychologists should approach career conversations holistically (i.e. consider demographic variables, such as the age, gender and race of the employee).

\section{Acknowledgements Competing interest}

The authors declare that they have no financial or personal relationship(s) which may have inappropriately influenced them in writing this article.

\section{Authors' contributions}

A.G. (University of South Africa) was the primary researcher and project leader, assisted by M.B. and E.C.R. (University of South Africa).

\section{References}

Babbie, E., \& Mouton, J., 2007, The practice of social research, Oxford University Press, Cape Town

Butterfield, L., Lalande, V., \& Borgen, B., 2009, Career conversations literature review, Report No. 5, Canadian Research Working Group, viewed 06 June 2012, from http://www.crwg-gdrc.ca/crwg/wp-content/uploads/2010/11/Report-5-CCLiterature-Review3.pdf Coetzee, M., Schreuder, A.M.G. \& Tladinyane, R., 2007, 'Organisational commitment and its relation to career anchors', South African Business Review, 11(1), 65-86.
Coetzee, M., \& Schreuder, D., 2009, 'Psychological career resources as predictors of working adults' career anchors: An exploratory study' South African Journal of Industrial Psychology, 35(1), 117-127.

De Vos, A., \& Hauw, S., 2010, Linking competency development to career success: Exploring the mediating role of employability, Vlerick Leuven Gent Management School, viewed 06 June 2012, from http://public.vlerick.com/ Publications/41770ac2-6aa9-e011-8a89-005056a635ed.pdf

Feldman, D.C., \& Bolino, M.C., 1996, 'Careers within careers: Reconceptualising the nature of career anchors and their consequences' Human Resource Management Review, 6(2), 89-112. http://dx.doi.org/10.1016/S1053-4822(96)90014-5

Hassan, G., Azizollah, A., Peyman, Y., Vahid, S., Solmaz, I., \& Narges, S., 2012, 'Relationship between career anchors and organizational commitment among faculty members' Journal of Studies in Education, 2(1), 58-70, viewed 04 March 2012, from http://www.macrothink.org/journal/index.php/jse/article/view/1439

Ituma, A., \& Simpson, R., 2006, 'Moving beyond Schein's typology: Individual career anchors in the context of Nigeria', Personnel Review 36(6), 978-995, viewed 3 March 2012, from http://www.emeraldinsight.com/0048-3486.htm

Jung, I., 2005, Perspectives on distance education lifelong learning and distance higher education, Commonwealth of Learning/UNESCO Publishing, Paris, viewed 05 June 2012, from http://www.mononeurona.org/files/userfiles/aarkerio_165. pdf\#page $=89$

Kidd, J.M., Hirsh, W., \& Jackson, C., 2004, 'Straight talking: The nature of effective career discussion at work', Journal of Career Development, 30(4), 231-245. http:// dx.doi.org/10.1023/B:JOCD.0000025113.48212.75

Latchem, C., Özkul, A.E., Aydin, C.H., \& Mutlu, M.E., 2006, 'The open education system, Anadolu University, Turkey: e-transformation in a university', Open Learning, 21(3), 22-235. http://dx.doi.org/10.1080/02680510600953203

Ramsey, C., 1998, 'Managing within conversation: Influencing for change', Career Development International, 3(7), 293-299. http://dx.doi. org/10.1108/13620439810240755

Ravid, R., 2010, Practical statistics for eduators, 4th edn., University Press of America, Lanham, MD.

Schein, E.H., 1978, 'Individual Careers', in J. Lorsch (ed.), Handbook of organizationa behaviour, pp. 155-171, Prentice-Hall, Englewood Cliffs, NJ.

Schein, E.H., 1980, Organisational psychology, 3rd edn., Prentice-Hall, Englewood Cliffs, NJ. PMCid:PMC1279231

Schein, E.H., 1985, Career anchors: Discovering your real values, University Associates, San Diego. PMCid:PMC1977195

Schein, E.H., 1987, 'Individual and careers', in J. Lorsch (ed.), Handbook of organisational behaviour, Prentice Hall, Englewood Cliffs, NJ. PMCid:PMC299361

Schein, E.H., 1990, Career anchors: Discovering your real values, Pheiffer, San Diego. PMCid:PMC1002566

Schein, E.H., 1993, Career anchors: Discovering your real values, Pfeiffer, London. PMCid:PMC2423672

Schein, E.H., 1996, 'Career anchors revisited: Implications for career development in the 21st century', Academy of Management Executive, 10(4), 80-88.

Schein, E.H., 2006, Career anchors: Facilitator's guide, 3rd edn., Pfeiffer, San Francisco.

Schreuder, A.M.G., \& Coetzee, M., 2006, Careers: An organisational perspective, 3rd edn., Juta, Cape Town. PMCid:PMC1809664

Silverman, D., 2010, Doing qualitative research: A practical handbook, 3rd edn., Sage, Los Angeles.

Singh, M., Bhattacharjee, V., \& Kodwani, A.D., 2009, 'Mapping career anchors in a large engineering company: A study', Paradigm, XIII(2), 51-56.

Tabachnick, B.G., \& Fidell, L.S., 2007, Using multivariate statistics, 5th edn., Pearson Education, Boston. PMCid:PMC2724990

Tan, H., \& Queck, B., 2001, 'An exploratory study on the career anchors of educators in Singapore', The Journal of Psychology, 135(5), 527-545. http://dx.doi. org/10.1080/00223980109603717, PMid:11804006

The Chartered Institute of Personnel Development (CIPD), 2005, Career discussions at work: Practical tips for HR, managers and employees, viewed 12 March 2012, from http://www.cipd.co.uk/hr-resources/practical-tools/career-discussions-tips. aspx

Walsh, K., \& Fisher, D., 2005, 'Action inquiry and performance appraisals: Tools for organizational learning and development', The Learning Organization, 12(1), 2641. http://dx.doi.org/10.1108/09696470510574241

Weber, K., \& Ladkin, A., 2009, 'Career anchors of convention and exhibition industry professionals in Asia', Journal of Convention and Event Tourism, 10, 243-255. http://dx.doi.org/10.1080/15470140903356411

Wils, L., Wils, T., \& Tremblay, M., 2010, 'Toward a career anchor structure: An empirical investigation of engineers', Industrial Relations, 65(2), 236-256. http:// dx.doi.org/10.7202/044301ar 